\title{
Notas ao Codigo Civil
}

\author{
Signal ou Arrhas
}

\author{
J. A. C.
}

Duas observações preliminares são indispensaveis á dedução das idéas na critica, que vamos fazer, das disposições do Codigo Civil sobre o signal ou arrhas.

A primeira é que não cogitaremos das chamadas arrhas penitenciaes, como as da Ord. 1.4 tit. $2 \S 1$, segundo a qual a estipulação arrhal conferia a qualquer das partes no contrato de compra e venda o direito de arrepender-se mediante a perda das arrhas.

O Codigo Civil não admitte as arrhas penitenciaes, pois que o direito ao arrependimento como está no art. 1095 resulta, não da dação do signal e sim de uma convenção especial (pactum displicentiae ou clausula de arrependimento) adjecta ao contrato, e nas promessas de contratos solemnes obviamente não é o signal dado que attribue ao contrahente a faculdade de negar-se a celebrar o contrato definitivo (art. 1088 do Codigo).

A segunda observação é que estudaremos os effeitos das arrhas primeiro nos contratos de forma livre ou não solemnes e depois nos contratos preliminares ou promessas de contratos. Diversificam tanto uns dos outros que o estudo em conjuncto de todos elles não poderia deixar de trazer desordem e confusão no assumpto. 
Dispõe o art. 1094 do Codigo: “O signal ou arrhas, dado por um dos contrahentes firma a presumpção de acôrdo final e torna obrigatorio o contrato"

Segundo essa disposição preenchem as arrhas duas funcções :

$10^{\mathrm{a}}$ - Firmam a presumpção de accordo final:

$2 .^{a}$ - Tornam obrigatorio o contrato.

Mas, se uma das funções das arrhas é "tornar obrigatorio o contrato", segue-se que, segundo o Codigo, ellas constituem um requisito da convenção, por outros termos, todas as vezes que houver arrhas é destas que resulta o vinculo obrigatorio, isto é, a propria formação do contrato. De onde decorre, como consequencia necessaria, que, si for nulla a estipulação arrhal, não será obrigatorio o contrato ou, o que é o mesmo, não produzirá effeitos juridicos.

Ora as legislações em geral e a doutrina attribuem ás arrhas duplo fim: attestar a formação ou existencia do contrato e assegurar-lhe a execução. A dação de arrhas suppõe o contrato formado, aperfeiçoado e a elle se addita para comprovar de modo inequivoco a conclusão do acordo e para reforçar a obrigação.

Por este ultimo effeito as arrhas podem figurar ao lado da pena convencional, do juramento (no antigo direito), da hypotheca, das intercessões.

Que as arrhas não eram em direito romano uma condição essencial de contrato vem affirmado categoricamente nos textos a proposito da compra e venda: quod sæpe arrhæ nomine pro emptione datur, non eo pertinet quasi sine arrha conventio nihil proficiat, sed ut evidentius probare possit convenisse de pretio" Dig. 18, 1, 35 .

Alguns interpretes teem entendido que no direito quiritario, depois que desappareceram as formas da antiga mancipatio, eram as arrhas que davam força obrigatoria aos contratos, não sendo sufficiente para isso o consentimento das partes. A insistencia com que as fontes affirmam que a compra e venda se formava independentemente das arrhas seria indicio de que se havia operado a transição do velho 
direito para o jus gentium, consoante o qual a vontade dos contrahentes, mesmo despojada de formas symbolicas, era bastante para dar existencia ao contrato.

Como quer que fosse, no novo direito romano não dependia do signal a formação do contrato. Nem o preço, nem as arrhas, diz Justiniano, são exigidas para que haja venda, porque o que é dado como arrhas é antes um signal de que a venda se aperfeiçoou; .nam quod arrhæ nomine datur, argumentum est emptionis et venditionis contractæ.

As legislações modernas não se apartaram neste ponto do direito romano. Salvo poucas excepções em que as arrhas apparecem com o caracter penitencial, é o antigo systema que tem prevalecido na regulamentação da materia pelos codigos actuaes (1). Assim o Codigo allemão dispõe no art. 336: "Si na celebração de um contrato deu-se alguma cousa a titulo de arrhas, esta dação vale como signal da conclusão do contrato"

Teria sido intuito de legislador brasileiro consagrar doutrina diversa, fazendo depender do signal a propria força obrigatoria do contrato? Ou a segunda parte do art. 1094 é um desses descuidos de que está inçado o Codigo e onde se diz cousa differente da que se pretendia dizer? Nós nos inclinamos pelo segundo modo de ver. No systema do Codigo basta o consentimento das partes para gerar os contratos consensuaes (não cogitamos agora dos contratos solemnes); o que os torna obrigatorios é precisamente esse acôrdo final, cuja presumpção, segundo a primeira parte do art. 1094, a dação do signal firma.

A interpretação literal do remate do art. 1094 nos conduziria a este resultado: nos contratos sem arrhas o vinculo contratual forma-se pela só vontade das partes; nos contratos com arrhas, por effeito dellas. Seria uma distinção nova e verdadeiramente injustificavel no direito moderno. Não é esse, parece-nos, o pensamento da lei. O que se quiz

(1) Em alguns estados confederados da Alemanha as arrhas eram antes do Codigo forma necessaria de determinados contratos. 
dizer no fim do art. 1094 é que o signal dado assegura o cumprimento do contrato.

Está escripto no art. 1096 que as arrhas devem ser restituidas quando o contrato for concluido. Por esta disposição literalmente entendida as arrhas se entregariam antes da conclusão do contrato para serem restituidas uma vez elle concluido. Como conciliar isto com as prescripções do art. 1094? Temos sem duvida outro lapso, outra prova de que nesta parte as palavras da lei não exprimem o seu pensamento.

Não é, pois, nenhum desarrazoamento affirmar que no final do art. 1094 o legislador não disse o que pretendia dizer.

Passemos ao art. 1096: "Salvo estipulação em contrario, as arrhas em dinheiro consideram-se principio de pagamento. Fóra esse caso, devem ser restituidas, quando o contrato for concluido ou ficar desfeito".

Eis uma disposição infeliz em todas as suas partes!

Preceitua ella em primeiro logar que, salvo estipulação em contrario, se imputem no pagamento as arrhas em dinheiro. Ora esta determinação nem sempre será exequivel.

E' preciso distinguir os casos em que ha homogeneidade entre o objecto das arrhas e o da prestação a cargo do contrahente que as deu, daquelles em que não se verifica tal homogeneidade.

Nos primeiros a imputação das arrhas no pagamento pode fazer-se, quer consistam ellas em dinheiro, quer não. Nos segundos a imputação não é possivel, qualquer que seja o objecto das arrhas.

Ordena o art. 1096 em segundo logar a restituição das arrhas quando o contrato fôr concluido.

Comprehende-se a obrigação de restituir as arrhas por occasião da conclusão do contrato, quando existe um contrato preliminar ou promessa de contrato solemne. Nesses casos a clausula arrhal tem por fim garantir a celebração do acto definitivo solemne, de modo que, concluido este, deve 
seguir-se a devolução do signal, salvo si for caso do desconto na prestação devida pela parte que o entregou.

Mas nos contratos não solemnes, que são os que a lei tem em vista nos arts. 1094 a 1097, a dação de arrhas suppõe o contrato concluido, perfeito e lhe assegura a execução. Como pois, entender a obrigação de restituil-as “quando o contrato fôr concluido", como se lê no art. 1096? Não tem sentido razoavel essa providencia. A nosso ver quiz o legislador dizer - quando o contrato for cumprido. Nessa hypothese bem: não sendo possivel o desconto no pagamento, deve o signal ser restituido.

Prescreve ainda o art. 1096 a devolução das arrhas "quando o contrato ficar desfeito"

Os contratos se desfazem (2):

a) por acôrdo das partes;

b) por effeito de condição resolutiva;

c) por impossibilidade da execução resultante de caso fortuito ou força maior.

Quando o contrato for dissolvido por acôndo das partes, si ellas não derem outro destino ao signal, terá este de ser devolvido em todos os casos e não sómente fóra do caso previsto na primeira parte do art. 1096, como ahi erradamente se diz.

Tambem será sempre obrigatoria a restituição das arrhas quando a dissolução do contrato resultar da impossibilidade casual de cumpril-o, como na hypothese do art. 865 do Codigo.

Assim qualquer que seja a causa do desfazimento do contrato, não se justifica a restrição do art. 1096 his verbis: "Fora esse caso.

Diz o art. 1097: "Si o que deu arrhas der causa a se impossibilitar a prestação, ou a se rescindir o contrato, perdel-as-á em beneficio do outro"

O termo rescisão applica-se tanto á annullação dos con-

(2) Não falamos na rescisāo judicial, que está prevista no art. 1097 e que deixa subsistir o direito á indemnização. 
tratos cf. art. 178, V - como á sua resolução por inadim. plemento - art. 1092 \& Unico.

Abrange o art. 1097 esses dois casos?

Não seria antijuridico impor á parte que deu culposamente causa á annullação do contrato a perda do signal. $O$ direito da outra parte á indemnização é perfeitamente admissivel como uma consequencia da culpa in contrahendo.

Pensamos, todavia, que o Codigo se refere á resolução judicial dos contratos por falta de cumprimento de obrigações delles decorrentes. Segundo o \& Unico do art. 1092 a parte prejudicada tem direito ao resarcimento das perdas e damnos; pelo disposto no art. 1097 ella, si tiver recebido signal, poderá guardal-o para si.

Mas, si o signal for insufficiente para compensar os prejuizos, poderá a parte exigir complemento de indemnização?

Em algumas legislações as arrhas, além de produzirem os effeitos que lhes são proprios, preenchem funções analogas ás da clausula penal. Assim ellas valem como prefixação dos damnos, de modo que não se pode attribuir á parte não culpada, a titulo de indemnização, somma superior ou inferior ás arrhas dadas - cf. Codigo italiano, art. 1230 , al. 2.

Nosso Codigo não é expresso; mas si ex vi do art. 1097 a parte culpada não tem direito a nenhuma restituição, quando a importancia do signal excede a das perdas e damnos, é preciso concluir que na hypothese inversa a outra parte deve contentar-se com o signal. Só assim será mantido neste ponto especial o principio da igualdade das partes nos contratos.

Por essa inferencia do art. 1097 pensamos que no systema do Codigo as arrhas representam para a parte que as recebeu a liquidação convencional das perdas e damnos provenientes do inadimplemento do contrato. De onde resulta que, si não se cumpre o contrato sem que a prestação se tenha tornado impossivel, a parte não culpada não terá direito ao mesmo tempo á obrigação principal e ao benefi- 
cio da convenção arrhal, mas terá que escolher entre uma cousa e outra.

$\mathrm{O}$ art. 1097, só prevê a culpa da parte que deu as arrhas; mas o contrato pode rescindir-se, ou a prestação tornar-se impossivel por culpa da parte que as recebeu. $E^{\prime}$ applicavel a essas hypotheses a solução do art. 1097? Parece-nos que não. Aquella disposição é derogatoria das normas communs ás quaes se devem subordinar os casos por ella não regulados explicita ou implicitamente. Ora, pelas regras geraes a parte que deu arrhas tem direito nas eventualidades do art. 1097 á restituição dellas (condictio sine causa ou reivindicação, conforme a hypothese) e a peridas e damnos segundo os arts. 865, 879, 1054 e $1092 \S$ Unico. Dest'arte o Codigo criou uma disparidade entre as partes, que fere o principio da igualdade ha pouco invocado e não se apoia em razões juridicas. O art. 1097 mutila a convenção arrhal e elle mesmo tem o aspecto de uma disposição mutilada.

Deixando de tratar dos contratos em que as arrhas são acompanhadas da clausula de arrependimento (art. 1095), casos raros e sem difficuldades praticas, passamos a dizer sobre os effeitos das arrhas nos contratos preliminares ou promessas de contratos solemnes, de acôrdo com a distinção feita no principio deste trabalho.

Nos contratos solemnes, cuja existencia legal depende de uma determinada forma, as arrhas não podem desempenhar a função probatoria. Mas os interessados podem fazer uma convenção preliminar em que se obriguem a celebrar o contrato definitivo solemne.

Desse contrato preliminar (pactum de contrahendo) não resulta acção para coagir directamente a parte a realizar o negocio principal - nemo potest precise cogi ad factum: em nosso direito nada, nem mesmo a sentença judicial, suppre o instrumento reputado essencial á formação do contrato pela lei ou pela vontade dos interessados. Si, portanto, uma das partes se recusa a cumprir o contrato preliminar (3),

(3) Suppõe-se uma promessa bilateral de contrato. 
isto é, a celebrar o contrato definitivo, á outra parte só resta o recurso de exigir indemnização das perdas e damnos cf. art. 886 do Codigo.

A faculdade de deixar de satisfazer nesse caso a promessa de contrato, commumente chamada direito de arrependimento, decorre da propria natureza da relação juridica, quer dizer, da impossibilidade juridica de coagir a parte a effeituar a prestação promettida em forma especifica.

Havendo, pois, no contrato preliminar dação de arrhas, preencherão estas o papel de pena e ao mesmo tempo de liquidação antecipada das perdas e damnos. Si a parte que fugir á obrigação de celebrar o contrato definitivo for a que deu as arrhas, perdel-as-á em proveito da outra; si for a que as recebeu, terá que restituil-as em dobro.

Tal nos parece a exacta doutrina sobre as funções das arrhas nos contratos preliminares ou pactos de contrahendo (4).

(4) Em these, quando as partes convencionam reduzir o contrato a escripto, isto pode ter duplo sentido. Ou ellas querem que o contrato seja obrigatorio independentemente da compilação do acto escripto, de modo que este é destinado apenas a facilitar a prova. Ou a forma convencionada é uma condição do contrato, isto é, as partes querem que a força obrigatoria do contrato dependa essencialmente da redação escripta do acôrdo. Segundo uma lei de JusTiniano (Cod. 4, 21, 17) em falta de declarações explicitas das partes deve-se admittir a segunda das interpretações expostas, pela qual nenhum dos contrahentes, baseado no simples ajuste preliminar, pode coagir o outro a executar o contrato, ou a realizar a forma combinada. Si decisão igual á dia citada lei de Justiniano resulta dos arts. 133 e 1088 do Codigo Civil é questão que não nos interessa agora. Apenas diremos que todas as vezes que houver dação de arrhas em convenções preliminares, a parte que desistir perdel-as-á si for a parte que as tiver dado; restituil-as-á addicionando-lhes seu valor em dinheiro, si for a que as tiver recebido. Estas soluções decorrem do final do art. 1088 combinado com o art. 1095.

Non obstat o art. 133, porque, segundo nos parece, tambem á hypothese prevista dessa disposição se applica o art. 1088.

$O$ assumpto demanda desenvolvimento que nos conduziria a materia extranha á do nosso trabalho. 
O Codigo Civil contem a respeito a defeituosa disposição do art. 1088: "Quando o instrumento publico for exigido como prova do contrato, qualquer das partes pode arrepender-se, antes de assignar, resarcindo á outra as perdas e damnos resultantes do arrependimento, sem prejuizo do estatuido nos arts. 1095 a 1097 "

Sem duvida o que se pretendeu dizer foi que na promessa de contrato solemne a parte que se recusar a cumpril-a, resarcirá á outra as perdas e damnos resultantes da inexecução, salvo o disposto.

A lei suppõe o contrato preliminar tendo por objeto a realização do contrato definitivo solemne e manda applicar, quando ha dação de arrhas, os arts. 1095, 1096 e 1097.

Quanto á applicação do art. 1095, cumpre ponderar que para que a parte possa arrepender-se, não ha necessidade de estipulação expressa, pois, como já vimos, nos contratos preliminares o direito de arrependimento decorre da propria natureza juridica do negocio ou, se quizerem, da lei (art. 1088).

Relativamente ao art. 1096 surge a difficuldade de entender a obrigação de restituir as arrhas "quando o contrato for concluido" Já expuzemos a unica interpretação razoavel dessa prescripção legal applicada ás promessas de contratos.

O art. 1097 não se ajusta bem aos contratos preliminares.

Com effeito um dos casos alli previstos - o da rescisão do contrato - confunde-se nas promessas de contratos solemnes com o do arrependimento, que é assegurado a qualquer das partes pelo art. 1088 e dá lugar á applicação do art. 1095.

O outro caso do art. 1097 - impossibilidade de prestação - devia tambem resolver-se, em se tratando de contratos preliminares, de acôrdo com o disposto no art. 1095, porque aos contrahentes é sempre facultado negarem-se á realização do contrato definitivo.

Entretanto, pelo que estatue o art. 1097, si a parte que tornou impossivel a prestação fôr a que deu as arrhas, per- 
del-as-á em proveito da outra; mas si for a que as recebeu, terá de indemnizar as perdas e damnos, segundo a regra geral do art. 879 !

Acreditamos ter demonstrado que toda a regulamentação da materia de arrhas ou signal no Codigo Civil é antiscientifica, em alguns pontos inintelligivel e contem soluções injustas.

Nós proporiamos a substituição dos arts. 1094-1097 pelos seguintes:

Art. 1 - A dação de arrhas num contrato valerá como prova de sua conclusão e como garantia de seu cumprimento.

Art. 2 - Salvo acòrdo em contrario, observar-se-ão as disposições seguintes:

I - Si o contrato se cumprir, imputar-se-ão as arrhas na prestação devida pela parte que as deu. Não sendo isso possivel, serão restituidas.

II - Tambem serão restituidas as arrhas, si o contrato se dissolver por acôrdo das partes ou por impossibilidade causal da prestação.

III - No caso de inadimplemento do contrato é facultado á parte não culpada guardar para si as arrhas recebidas ou demandar em dobro as que tiver dado, quando não prefira exigir a prestação estipulada.

IV - Si o contrato se rescindir ou a prestação se tornar impossivel por culpa de uma das partes, perderá esta as arrhas ou restituil-as-á em dobro, conforme o caso.

Art. 3 - A' parte que deixar de cumprir um contrato preliminar applicar-se-á o disposto no artigo anterior n. IV.

Art. 4 - Como o art. 1095 do Codigo Civil.

Si se prefere não dar á convenção arrhal o caracter de liquidação antecipada das perdas e damnos, as disposições dos ns. III e IV devem ser substituidas por esta: 
III - As arrhas serão imputadas na prestação de perdas e damnos devidos á parte que as recebeu, quando por culpa da outra parte houver mora no implemento da obrigação, o contrato se rescindir ou sua execução se tornar impossivel.

Não sendo possivel essa imputação, serão as arrhas restituidas mediante a satisfação das perdas e damnos. 